\title{
C:\%ั:VID-19
}

\section{Infected with COVID-19: One psychiatrist's story}

\section{A physician and his wife describe their experience after they both contracted the virus}

Emil: Coronavirus disease 2019 (COVID-19) wasn't really on my mind until the first weekend in March, specifically Sunday, March 8, 2020. That weekend had us traveling from Chicago to Berwyn, Pennsylvania to attend the funeral of one of my older cousins. Though we were the only ones from his side at the graveside, his funeral had drawn numerous relatives, none of whom were "socially distanced."

On our way home, I received an e-mail from a colleague in Brazil who had invited me to speak at a conference in São Paulo. He told me that several of my American colleagues had contacted him and informed him that their universities had banned travel because of COVID. "I'm coming," I replied. "I don't think COVID's going to be a big deal here." He said COVID wasn't a "big deal" in Brazil, either. Famous last words.

The next weekend, I left early on Saturday morning to start my call duty at the hospital. After finishing rounds at one hospital and going to the next, I got a text from my wife, Anne, asking "What's wrong with your people over there? What kind of doctors would take a 65-year-old colleague with a history of asthma, and history of an ICU stay with 10 days on a respirator with acute respiratory distress syndrome 10 years ago, and have him exposed to this lethal virus? Are they trying to kill you?"

It stopped me in my tracks. She was right. A lot had changed in a week. In that single week, it had become clear that COVID was a real threat, and I was vulnerable. I finished my call duty but made it clear to the "powers that be" I was going to stay

\section{Disclosures}

The authors report no financial relationships with any companies whose products are mentioned in this article, or with manufacturers of competing products.

doi: $10.12788 /$ cp.0058

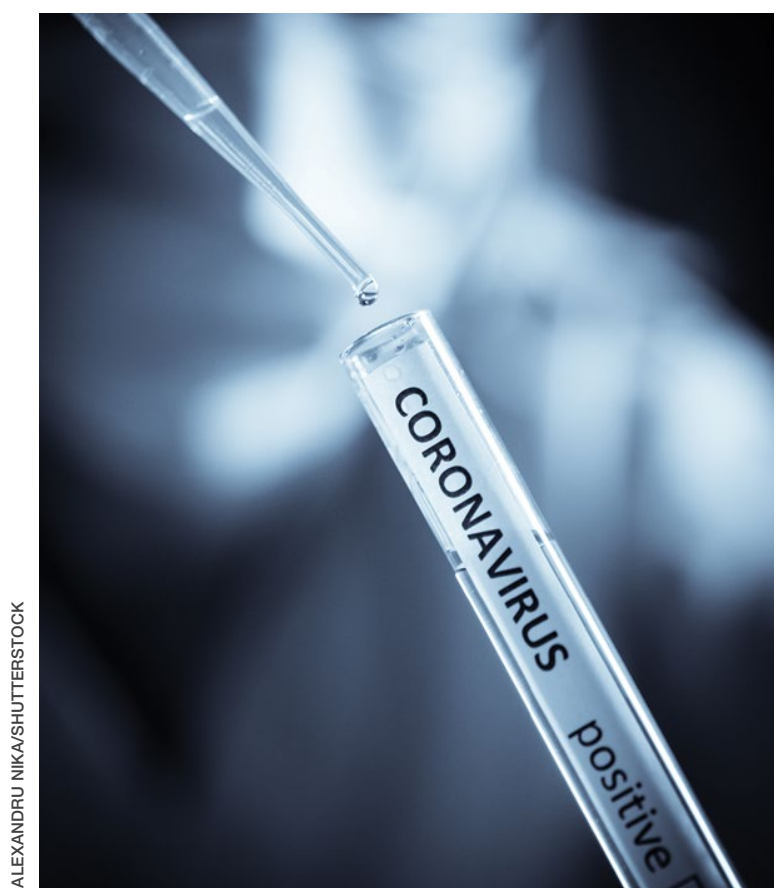

Emil F. Coccaro, MD

George T. Harding III, MD, Endowed Chair in Psychiatry Professor and Vice Chair for Research

Department of Psychiatry and Behavioral Health The Ohio State University Wexner Medical Center Columbus, Ohio

Anne M. Miles, Esq.

Adjunct Professor

Moritz College of Law

The Ohio State University

Columbus, Ohio 


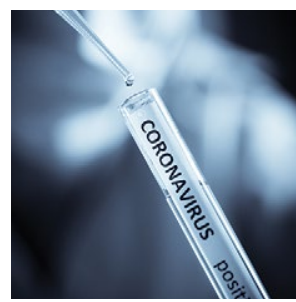

Infected with COVID-19

\section{Clinical Point}

The next morning, I went for a COVID test, but by then I already knew the result. It was positive, as was the one for Anne

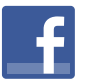

Discuss this article at www.facebook.com/ MDedgePsychiatry home and isolate for the next few weeks, until we knew more. I was ahead of the curve, but not by much: within days, Chicago shut down with a "stay-at-home" order.

Anne: When the threat of COVID first became known, I said to family and friends, "If Emil gets this, it's going to be very, very bad." After that, we made certain to wear masks and gloves when we went out, which wasn't often.

Emil: We stayed in for the next 3 months until we moved to Columbus, Ohio for my new position as Vice Chair for Research in the Department of Psychiatry and Behavioral Health at The Ohio State University Wexner Medical Center (OSUMC).

The day after arriving, I went to the emergency dental clinic because of a severe toothache. While they couldn't save my tooth, I got something in return: COVID. The clinic took more than appropriate precautions, but I was in a very large room, not a private office, with many patients having their teeth drilled and whatever it is dentists do (actually, I do know; my father was a dentist).

All was fine until 2 days later, when I began to feel a bit "unwell" on late Friday afternoon. I went out to do some chores the next morning, but soon returned home exhausted. The rest of the weekend was more of the same, and I was surprised at how I just couldn't get anything done. On Monday, I felt a chill and thought I might have COVID.

The next morning, I went to OSUMC for a COVID test, but by then I already knew the result. The night before, Anne started complaining of a dry cough that would not stop.

Anne: When I realized Emil had COVID, I wrote to a friend, "If he gets bad and has to go to the hospital, or worse ... he goes on a ventilator, I may need to be admitted to a psych ward!" I was still upset from the memory of sitting by Emil's bedside when he was sick, and on a ventilator, 10 years ago, with his doctors talking with me about when, not if, he died.

Emil: My test came back within 8 hours on Tuesday. It was positive, as was the one for
Anne the next day. The doctor I spoke to that evening thought I was only having a mild case and that I should just stay isolated. We immediately got a thermometer and a pulse oximeter to follow our symptoms. Anne's oxygen saturation levels were always above 95\%, but mine were lower, and by Friday, 3 days later and 1 week after my first symptoms, they were down to $92 \%$ or less. At that point, we both went to the ER at OSUMC.

Anne: We went to different places in the ER to be evaluated. As Emil was being wheeled away in the ER for his evaluation, I ran over for a kiss-with our masks on.

As my ER evaluation was concluding, my doctor said, "I want someone, preferably the same person, to check in on you every day." I replied I had a friend who is a critical care nurse. He smiled and said, "Excellent." My friend called every day, and when she didn't like how I sounded, on some days, she found an excuse to call again.

Emil: I barely recall my ER evaluation, except that I was to be admitted for observation and supplemental oxygen. I accepted this with aplomb, knowing I was in good hands and hoping I'd be home soon.

Anne: Because we were in the same ER, I thought I'd be able to see Emil once they decided to admit him. No. They wouldn't even let me go to him to get his wallet for safekeeping. Instead, it was brought to me in a hazmat bag. Thus began our forced separation for the next 5 weeks.

Emil: I had to wait hours for a bed and was wheeled up late in the evening to a double room with one other patient, also with COVID, I supposed. While I had an oxygen mask on, we were only separated by a curtain. I had no idea I wouldn't see Anne for weeks.

Anne: I returned "home" to a house I had spent less than 5 days in. We had barely moved in and it only had a bed, a couch, a $\mathrm{TV}$, and a kitchen chair. I didn't even know my neighbors to wave at, and ... I was in quarantine. No one could come to me. Our eldest daughter was alone near Burlington, 


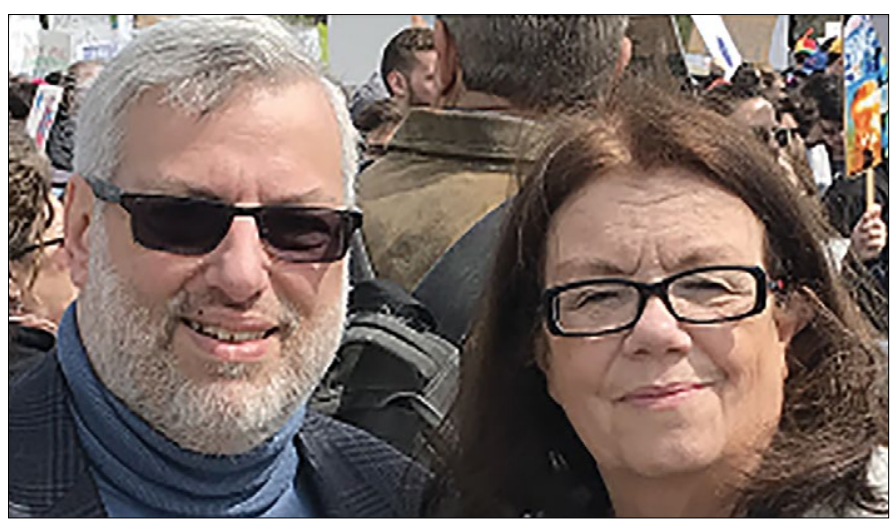

Vermont (where she had escaped to from New York City when it was the national epicenter for COVID back in March). Our youngest daughter was alone in Los Angeles, and our son, a newly minted First Lieutenant in the Army, was stationed in Afghanistan. "Good for him," I thought. He could safely interact with his army buddies. It was so ironic; the one in the war zone was the only one of us who was safe from COVID.

I reached out to family and friends and asked for prayers. Emil was prayed for by all of our Catholic, Methodist, Jewish, Muslim, and Buddhist friends. As I told him later, he was prayed for from Afghanistan to Alaska. My extended family activated a text chain so all I had to do was reply and everyone on the chain would have the same information. I also received many notes and cards of support from friends and Emil's family. Many told me how strong I was and how I would be fine. Later, I realized how many of these were from widows who were telling me I would survive bereavement, should that be the outcome.

Emil: The next day, the doctors started me on a 5-day course of the newly "approved" antiviral remdesivir, and the day after that, I received 2 units of convalescent plasma on "compassionate use" from the Mayo Clinic. It didn't matter. I kept getting worse.

Anne: I received twice-daily updates from the nurses. When the updates were late in coming, I crawled the walls, waiting at least 2 hours before reaching out. One day, the nurse who answered said she couldn't talk because his nurse was dealing with an emergency with him. I didn't take a deep breath until his nurse called back to say he was stable. Regardless, he just kept getting sicker and sicker, and I began to fear he would not make it.

Emil: By Day 5, my X-ray showed clear evidence of a bilateral pneumonia (it had appeared "normal" on admission) and I was transferred to a "step-up unit." The next day, I was transferred to the ICU and placed on a ventilator, in the prone position, for 16 hours a day.

Anne: The day Emil was transferred to the ICU, he told me he was worried about his fate. He called and asked me to stay on the phone with him while waiting to go to the ICU. We were both so weak we couldn't do more than say "I love you" and listen to the other's labored breathing. That was our last phone call until he was off the ventilator 10 days later.

Emil: At this point I had no idea what was going on. I was on a ventilator and I was "out."

Anne: In the meantime, my family made sure I knew they were thinking of us. Every day I woke up with a text from one cousin asking how the night was while my sister checked in every afternoon. They sent flowers and baskets of goodies. Knowing how difficult it was waiting for updates, they sent me a jigsaw puzzle with a thousand pieces. I was surprised at how important that was for binding my anxiety. A friend sent books from my favorite writers.

Despite all this, I was absolutely beside myself the night Emil was placed on the

\section{Clinical Point}

The doctors started me on remdesivir and I received convalescent plasma. It didn't matter. I kept getting worse 


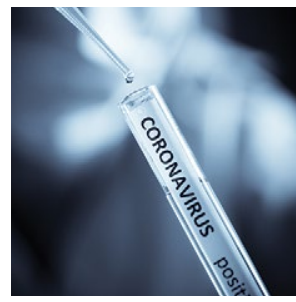

Infected with COVID-19

\section{Clinical Point \\ It was surreal; like watching myself die off in the distance, emotionally disconnected from the whole scene}

ventilator. I cleaned and scrubbed the house; not that it needed it, I needed it. In the bedroom I saw a bottle under the bed. I retrieved it but couldn't get up off the floor. I was weak and had tremendous muscle pain each time I moved. I had my phone, so knew I wouldn't be stranded, but ... I didn't relish the idea of calling 911 and have them break down the front door in their hazmat suits. After more than 30 minutes, and much effort, I was able to get myself up; soon after, I put a house key outside.

When a friend who was taking care of our 2 dogs in Chicago heard that Emil was on the ventilator, she drove through the night to bring them to me so I would have them for solace. She couldn't even come in the house. She stayed at a nearby hotel and visited with me from outside with masks on waiting for the updates.

Emil: Being an elder lawyer married to a physician, Anne knows a thing or 2 about medicine (because she's seen a thing or 2 about medicine). She's even been known to give her elderly clients Mini-Mental State Exams. In addition to talking with members of her support system, Anne was also talking with friends and relatives who are physicians. One exclaimed, "He's having a cytokine storm!" and said I needed steroids. Another said, yes, that and serious "anti-inflammatory" drugs. At that moment, data supporting the use of steroids or "anti-inflammatories" in COVID hadn't yet become public. The data on steroids came out early the next week in the Lancet and the data on "anti-inflammatories" was still in process until a few weeks later.

Anne was ahead of the curve and advocated hard for both treatments. At the same time, my OSUMC physicians were considering other options for me. They were checking on my inflammatory status by following my levels of C-reactive protein (CRP) and interleukin-6 (IL-6). On Days 2 and 3, my CRP level was $64 \mathrm{mg} / \mathrm{L}$ and my IL-6 level was $32 \mathrm{pg} / \mathrm{mL}$ (neither should be higher than 1).

While I don't recall much before being on the ventilator, I do recall my alarm at seeing my CRP/IL-6 levels go up in real time on alerts from "My Chart" (my CRP/IL-6 levels were 149/123 within 4 days of admission, and reached a high of about 250/190 as
I entered the ICU). I knew what those numbers meant. It was surreal; like watching myself die off in the distance, emotionally disconnected from the whole scene.

The decision to give steroids was relatively easy, and I was started on dexamethasone, a very inexpensive steroid, on Day 7 (ICU Day 2). The decision of which "antiinflammatory" to give was more difficult, as OSUMC had over 40 treatment protocols for COVID. Anne suggested 2 drugs based on recommendations from our physician friends-tocilizumab and acalabrutinibboth were on the market for other conditions and very expensive. The first is an IL-6 antagonist, while the second shuts down cytokine production in B cells, an effect also observed in lung tissue. While tocilizumab was not included in any of the OSUMC COVID protocols, acalabrutinib was, and I started on that medication on Day 8 (ICU Day 3).

Anne: My experience being the advocate was different than the first time 10 years before. That time, Emil had a community-acquired pneumonia, with which our doctors had much experience. This time, I was more active because no one had much information about how to deal with COVID and, thus, there was no standard of care. In fact, Emil was only the second patient to receive acalabrutinib at OSUMC; later, we found out that that patient did well.

Emil: The "anti-inflammatory" strategy worked. Within 5 days of starting the 2 drugs, my CRP and IL-6 levels were down to 10 and 5, respectively; a reduction of $>95 \%$. As these levels dropped, so did my oxygen requirements.

Anne: Emil was finally on the upswing. I woke up the next morning and, surprisingly, found that my first emotion wasn't one of terror. His ICU doctor, a real booster for Emil, made it her mission to get him off the ventilator before the end of her ICU service week. She succeeded.

Emil: Five days after coming off the ventilator, I went to a rehab unit for reconditioning and to begin the long process of recovering my strength and stamina. 
Most people say to me, "How awful for you! How terrible!" I smile and say, "Yeah, well, I missed all the excitement. It was really much worse for Anne." I told them that, although you don't recall anything while on the ventilator, you get retrograde amnesia for the several days prior to artificial ventilation. I have texts on my cell phone, written by me in those first few days, I don't recall writing. Anne says we had conversations all the way up to my admission to the ICU; I recall none of those. Frankly, that's for the best.

One thing to highlight is that your brain doesn't stop working while you're "out." I had numerous vivid dreams, or whatever they were, while on the ventilator and after. Many were "bizarre and dark," others were "dark and bizarre." A few were amusingin the end. I recall watching a TV news program segment describing how we donated our 2 little dogs to the Queen of England, who then gave them to her youngest son, Edward. I swear, I actually "saw" this TV program and watched the Queen and her son (and his wife) playing with our dogs. I was so convinced, I asked Anne where our dogs were; with her, of course. No, she assured me, we hadn't given them to Queen Elizabeth II. Another conversation I swore I had with Anne was one in which she was telling me she was starting the vetting process to be a VP candidate for Joe Biden (Anne had been involved in Chicago politics so ... not totally "crazy"). Nevertheless, I was quickly disabused of this one by my eldest daughter, also a lawyer.

Anne: This time, like the last time he was on a ventilator, Emil took a few more days to clear all the drugs keeping him sedated. Last time, his medical center sent his colleague, the Chair of Neurology, to check on him because there was a concern that he wasn't "clearing" fast enough. This time, I was the one reassuring the doctors and nurses to be "patient." At the same time, I was disabusing him of his far-fetched idea that he was head of all research at OSUMC and head of the ICU. He told me, "I don't understand it. Don't these people know they work for me?" "No," I told him. "You are a patient there, and you need to behave." Aside from that, Emil was fairly lucid. As one of his nurses said, "He's oriented, he's just wrong!"

Emil: Some people have asked me if this experience has changed my perspective. It could have, but I went through something worse 10 years ago when I was first brought back from the "mostly dead." After that, I realized the most important things in life are the people you love and the people who love you; the good stuff is "gravy" and everything else isn't worth spending much time or energy on. The first thing I said to Anne when we were face-to-face, as I entered the rehab facility (with masks on, of course), was "I can't do this to you again."

Anne: One of the most inhumane aspects of COVID is that you can't be with your loved one while they are sick. Last time I spent 10 to 12 hours a day at the bedside. This time I couldn't be there at all. It was especially hard because I knew from the last time how much my presence meant to him. If I left, he would get agitated. His heart rate would come down by 10 beats when I sat next to him.

When we had our first post-ventilator conversation on Father's Day, he was surprised I was so excited to talk to him. Somehow, he thought I had abandoned him. What he didn't know was that I was thinking about getting a job in Housekeeping at the hospital just so I could go see him!

Emil: In the end, I'm now back to baseline and grateful I'm alive. I still have things I want to do professionally and personally, and am appreciative I'll have more time for those. However, I am appalled at how a serious public health issue has been turned into a political weapon by "science deniers" and that this is continuing to kill our citizens. That's not a nightmare from when I was ill. It's the "day-mare" we are living now.

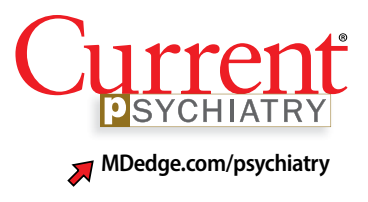

Clinical Point

I am appalled at how a serious public health issue has been turned into a political weapon by 'science deniers' 